\title{
Understanding HIVIAIDS and STIs as Related to Sexually Risky Behaviour by Higher Education Institutions Students: A Literature Review
}

\author{
Matjhabedi E. Mazibuko \\ Vaal University of Technology, \\ Private Bag x021, Vanderbijlpark, 1911 South Africa \\ Email: chabi.mazibuko@gmail.com \\ Nkgopole Nkune \\ Vaal University of Technology, \\ Private Bag x021, Vanderbijlpark, 1911 South Africa \\ Email: lesanaka@webmail.co.za
}

Doi:10.5901/mjss.2014.v5n14p380

\section{Abstract}

Basic knowledge about the spread of human immunodeficiency virus (HIV) and safe sexual practices has a critical impact on prevention of the acquired immunodeficiency syndrome (AIDS) and other associated STDIs. The problem among students at higher education institutions (HEIs) is that they are a high risk group for contracting HIVIAIDS and STIs due to uninformed decisions that they make. This study aimed to explore the knowledge and attitudes of higher education students towards HIV/AIDS, sexual transmitted infections (STIS) as related to their sexually risky behaviour. This literature review revealed that most students engage in unprotected sex and that some students fear taking an HIV test. Since young people are the future leaders, there is need to educate them about the consequences of unprotected sex. Our communities need to stand together and educate the young people about the dangers of having multiple partners and unprotected sex. Many of students have substantial knowledge about and positive attitudes towards the use of condoms in preventing STIs, HIV infection and even pregnancy. There is enough evidence that alcohol abuse significantly contribute to inconsistency in condom use by students.

Keywords: Sexually risky behaviour, HIV/AIDS and STIs, Higher education institutions;

\section{Introduction}

The issue of sexual behaviours of higher education students has generated a lot of interest among researchers (Cross and Morgan 2003; Higher Education HIV and AIDS Programme (HEAIDS) 2009; Mwaba and Naidoo 2005). For example, the (HEAIDS) Higher Education HIV and AIDS Programme (2009) conducted a comprehensive HIV prevalence as well as knowledge, attitude, behaviour and practice (KABP) study in the tertiary education sector of South Africa in order to enable the higher education sector to understand the threat posed by the epidemic to its core mandate. A total of 23605 (79.1 percent) out of 29,856 participants completed the questionnaires and also provided specimens for HIV testing. The study found that the mean HIV prevalence for students was 3.4 percent. This article explores whether being a student in a tertiary educational institution influences attitude and awareness of condom use.

Knowledge about the spread of HIV and safe sexual practices has a critical impact on the prevention of HIVIAIDS globally. HIVIAIDS is a major public health problem globally and in South Africa. According to estimates made by the Department of Health (South Africa) 5.2 million adults and children were living with HIV in 2008 representing $10.6 \%$ of the population (South African Department of Health, 2010; HEAIDS, 2010).

In the context of overall prevalence of HIV in all institutions, workplaces, and communities in South Africa, Higher Education Institutions (HEIs) are affected and impacted upon by HIV and AIDS the most.

Furthermore, there is a growing trend amongst female students that most of them are becoming pregnant and this implies that students are not using condoms when having sex (Mapfumo, 2007). Research also shows that male students are engaging in risky sexual behaviour (Cong et al. 2006; Kamali, Naar-King, Shah, Stanton, Thomas, Wang B, 2007). This issue has become a societal problem, because some students might not be able to carry on with their studies due to ill- health and pregnancy. This study sought to investigate the following research questions: (i) What are the sexual behaviours of students in Higher education belt towards safe sex? (ii) Level of students' awareness on HIVIAIDS and 
other STDIs (iii) What is the attitude of students on safe sex? And (iv) Which preventive measures do students engage in to protect themselves from sexual infections and diseases.

\section{Understanding HIVIAIDS and STIs as Related to Sexually Risky Behaviour}

\subsection{HIVIAIDS and STDIs transmissions}

In South Africa, as in many other developing countries, the primary method of HIV transmission is heterosexual intercourse (Shobo, 2007) and most South African youth know that HIV can be transmitted this way (Eaton and Flisher, 2000). Among South Africans aged 15-24, more than half have had sex by age 18 (Shisana, 2005), which then suggest that more than half of first year students at institutions of higher learning in south Africa have had sex before enrolment

Although not all sex is risky sex (e.g., the probability of HIV infection is reduced if condoms are used consistently or if individuals have only one, uninfected sexual partner), engaging in first sex is the entry point to subsequent risk behaviour. Thus, compared with youth who initiate sex at an early age, youth who delay sex spend fewer years of their lives at risk of HIV infection. For this reason, first sexual intercourse is considered HIV risk behaviour (Shisana, 2005).

\subsection{Youth attitude towards HIVIAIDS and STDI's}

Despite high HIV prevalence and high rates of sexual risk behaviors in South Africa and other Sub-Saharan African countries, young people in these countries often perceive themselves as being at low risk of HIV infection (Ajzen and Fishbein, 1980; Barden, 2004). One explanation for this is that youth may underestimate risks in general because of a feeling of invulnerability (Macintyre, 2004; Moore and Rosenthal, 1991). Additionally, HIV and AIDS are highly stigmatized in South Africa (Maughan-Brown, 2006). Because acknowledging one's own risk admits the possibility of being part of a stigmatized group, youth may avoid this by downplaying their personal risk (Macintyre, 2004)

Most research on the relationship between HIV risk perceptions and risk behaviors in Sub-Saharan Africa has looked at such variables as condom use and number of sexual partners. These studies have produced mixed results, with some finding correlations between HIV risk perceptions and risk behaviors (Shobo, 2007; Maharaj, 2006). Relatively little research in Sub-Saharan Africa has examined first sexual intercourse as a risk behaviour associated with perceived HIV risk. Some cross-sectional research indicates that individuals may remain sexually inexperienced out of concerns about HIV infection (Gersovitz, 2005; Simbayi, Chauveau and Shisana, 2005)

\subsection{Youth sexual behaviour}

A large proportion of those at risk of acquiring HIV are youths, especially those involved in unprotected sex, illicit drug use and prostitution (UNAIDS 2008). an estimated 6000 youths are infected with HIV globally and of the 15-24 year old young people living with HIV, 63 per cent are in sub-Saharan Africa (UNAIDS, 2008). There is a need to encourage youths to curb risky sexual behaviour and to take the test. Some studies have been conducted on sexual behaviors and condoms use pattern among youths in various African settings. A study in Malawi showed that there was a poor rate of HIV testing (19\%) among university students and a considerable number of the students had multiple sexual partners in the last 12 months (Ntata, Muula, Siziya and Kayambazinthu, 2008). A similar study in Madagascar, showed that most (80\%) of the students had sex before and only $6 \%$ used condoms consistently in the last 12 months citing reasons such as steady partners and decrease of pleasure (Rahamefy, Rivard, Ravaoarinoro, Ravaivoharisoa, Rasamindrakotroka, Morisset, 2008). Some Nigerian studies showed that only about $30 \%$ students in a Nigerian university had ever been tested for HIV and some students had over three sexual partners at a time (Ike \& Aniebue 2007). These recent statistics among young people in an enlightened setting shows that the awareness and attitude towards the disease is very poor (Ike \& Aniebue, 2007).

\subsection{Prevention, control and treatment}

The control of new infections in Africa is an emerging focus and basic prevention services that have been advocated to be effective are; education about risks of HIV, Voluntary Counselling and Testing, access to condoms, treatment for sexually transmitted infections, strategies to prevent mother to child transmission of HIV and harm reduction programmes for injecting drug users (Weller \& Davis, 2002). Condom use provides $80 \%$ protection against HIV, compared with nonuse, if used consistently (Davis \& Weller, 1999). There are also claims that irrespective of other risky sexual behaviors, 
consistent condom use has been demonstrated to be an effective means of preventing the acquisition and transmission of HIV and other STDs (Pinkerton \& Abramson, 1997). Consistent condom use among youths has been found to be poor in most African settings with more than half of them indulging in unsafe sex, especially in young women (Da Cruz, 2004).

This study was aimed at (1) evaluating students' attitude towards HIVIAIDS and STDIs condoms use, and their sexual behaviors (2) assessing the effect of demographic variables (age, age of sexual debut, gender and marital status) on students' attitude towards sex and HIVIAIDS and their sexual experiences.

\section{Potential Determinants of Condom Use}

\subsection{Gender}

According to ASSA2008 projections for 2011, South African women aged 15 to 24 have a prevalence rate of $12.85 \%$, while men in the same age range have a prevalence rate of 1.93\% (ASSA, 2008). These statistics indicate that in 2011 women has a prevalence rate that is approximately six times greater than men. This high prevalence rate is partially due to the female biological make up, but there are other factors that arguably contribute towards this increased risk for women. Some analysts point to women"s inferior social status" in Southern Africa and their financial dependence on men, specifically in the poorer households (Human Science Research Council, 2002). These factors are seen as constraining females" sexual decision making ability, especially in contexts tainted by coercion and violence (HIV In-Site, 2001), (WHO/UNAIDS, 2000).

\section{Potential Determinants of Condom Use}

According to a South African National HIV Survey, 8.7\% of people between the ages of 15 and 24 were living with HIVIAIDS in 2008 (Shisana, 2009). Since the majority of university students" fall within this age bracket, one might expect university students to exhibit similar statistics. This is not so, according to research by HESA (2008) students across the country have a prevalence rate of $3.4 \%$; less than half the national rate for the same age group. This suggests that university students are at a substantially lower risk of contracting HIV than non-students of the same age.

\subsection{Age}

There are different hypotheses regarding how age affects the decision to use a condom. One possibility is that with age comes a heightened sense of responsibility. If so, then all other things equal, the decision to practice safe sex should be more likely amongst older people. Another argument may be that as age increases so does the seriousness of the relationships one enter into, and this may have the effect of decreasing condom use since more serious relationships involve higher levels of trust. An interesting argument presented by Peltzer (2000), in a paper titled "Factors Affecting Condom Use among South African University Students", suggested that at young ages people are less embarrassed to propose the idea of condom use to their partner and less likely to be offended when using a condom is proposed.

\subsection{Socio-economic Status}

A model for condom use developed by Grebe and Nattrass (2011) indicates a positive relationship between condom use and household income. Further research into this matter indicates that this relationship is far more pertinent for African males than it is for African females (Grebe \& Nattrass, 2011). Grebe and Nattrass go on to explain that the wealthier the African male, the greater the prospects are of attracting multiple sexual partners, whether it be through transactional sex, sex work or multiple concurrent partners (Grebe \& Nattrass, 2011). Bezabih, Mannberg \& Visser (2010) investigated the relationship between expected future income and sexual risk taking. Their findings indicated that current household income has a negative relationship with the sexual risk taking however; their results relating to the effect of expected future income are relatively inconclusive (Bezabih, Mannberg \& Visser, 2010).

\subsection{Years of Schooling}

Education teaches people to think for themselves, giving them greater power to make decisions concerning their lifestyle and health (Peters, Baker, Dieckmann, Leon, \& Collins, 2010). It is also possible that more years of education is associated with a greater understanding of HIV, and the need to protect oneself actively against it. Research conducted 
before 1996 found that there was very little correlation between levels of education and HIV prevalence in Sub-Saharan Africa (Hargreaves, et al., 2008) which suggests that it was unlikely for there to be a relationship between education and condom use either. However, since the mid-1990s further research has shown that HIV prevalence is typically lower amongst the higher educated than amongst the lower educated groups. A possible reason for this may be that as more and more reliable information has been gathered about HIV; schools have integrated it into their curriculums (Hargreaves, et al., 2008); (Baker, Collins , \& Leon, 2008). If it is true that schooling exposes people to HIV education, then it should follow that the greater the number of years one spends in school, the more likely one is to use a condom. We thus include years of schooling as an explanatory variable.

\subsection{Knowledge about HIV}

According to the UNAIDS Global Report (2010), less than half of 15 to 24 year olds living in South Africa can correctly answer five basic questions about HIV and its transmissions. This lack of knowledge about HIV has caused South Africa to consistently fall short of the global targets for comprehensive knowledge set in 2001 (UNAIDS, 2010). This may affect condom use, however the cross national evidence on this is mixed (Lammers, van Wijnbergen \& Willebrands, 2011).

\subsection{Duration of a Relationship}

There is evidence that condom use within relationships decreases over time and eventually ceases altogether (Burgard, Kusunoki \& McGraw, 2008). This has been linked to enhanced trust and related perception that they are no longer at risk of infection. We thus include a variable for length of sexual relationship in our model of condom use.

\subsection{Older Sexual Partner}

Research has shown that young people, in particular young women, who have older partners, are far less likely to use a contraceptive than people who have partners of similar age. This behaviour may be caused by an uneven power distribution within the relationship, with the older partner possessing more power over decisions about their sexual encounters (Burgard, Kusunoki \& McGraw, 2008). We thus include a variable constructed as the difference in ages between the sexual partners, where a respondent with an older partner records a positive number of years and a respondent with a younger partner records a negative number of years.

\subsection{Concurrent Multiple Sexual Partners}

Trend analysis indicates that there has been a general decrease in the percentage of people, living in Sub-Saharan Africa who have multiple sexual partners; however, South Africa is an exception to this trend (UNAIDS, 2010). The persistence of concurrent relationships in South Africa is a difficult problem to solve since the acceptability of concurrent partners differs depending on one's cultural and spiritual background. A series of focus groups conducted in Khayelitsha, a large township situated outside of Cape Town, indicated that concurrent partnerships were common in their community, and while they are not discussed publically, they are accepted as a fait accompli in their study. Mah and Maughan-Brown (2009) found that the two main reasons for concurrent sexual partners amongst Khayelitsha residence are material or financial gain and sexual frustration or inadequacy. When asked about the link between concurrent partnerships and HIV most respondents acknowledged that having concurrent partners increased the risk of contracting HIVIAIDS, however, this knowledge does not seem to discourage the presence of concurrent partnerships (Mah \& Maughan-Brown, 2009). In many concurrent partnerships the respondent will have two categories of partners, a main partner and side partners. It has been found that respondents use condoms with their side partners far more consistently than with their main partner (Lansky, Thomas, \& Earp, 1998). An explanation for this may be that the frequency of condom use may decrease as the duration of a relationship increases (Lansky, Thomas, \& Earp, 1998); Burgard, Kusunoki, \& McGraw, 2008).

\section{Concluding Remarks}

Gender, race and personal experience with HIVIAIDS are variables that may be important for both risk behaviors (including entry into first sex) and perceived risk. Personal experience and familiarity with HIVIAIDS may be associated with more awareness of infection pathways, less stigma toward the disease and higher perceived risk of HIV infection. Many young South Africans know about HIVIAIDS first-hand: Among South Africans aged 15-24, 26\% know someone 
living with HIV, and 45\% know someone who has died of AIDS (Pettifor, 2004) Yet, studies have found either no relationship between risk behaviors and knowing someone living with HIV or someone who has died of AIDS, or a relationship in some groups but not others (Ukwuani, Tsui \& Suchindran, 2003) Evidence of a relationship between knowing someone living with HIV or someone who has died of AIDS and greater perceived risk among young people in Africa has also been mixed (Macintyre, 2004).

In their study to determine sexual practices and attitudes toward premarital sex and condom use among a sample of South African university students, Mwaba and Naidoo (2005) found that half of the participants reported having sex within 12 months of their arrival on campus and 8 percent indicated that they had been coerced into having sex by their partners. Although two-thirds of the participants reported that between 18 and 21 years was a good age to have sex; 43 percent approved of sex before marriage; and over 80 percent of the participants reported that they would refuse to have sex if their partner was unwilling to use a condom. However, the same study found that the majority of participants practice safe sex and are aware of the consequences of having unsafe sex. It is clear from the above study findings that some university students engage in premarital sex. In a similar vein, Cong, Kihara M, Ono-Kihara, Ravar, Zamani (2006) conducted a study to determine sexual behaviours and attitude towards safe of 22493 undergraduate students in two universities in Ningbo, China. Cong et al. (2006) found that condoms were never/ rarely used by 35 percent of sexually active students in both genders.

Multiple research results indicated that participants had knowledge about HIVIAIDS and Sexually Transmitted Infections (STIS). (Castora, 2005) found that knowledge about sexual issues and attitudes toward condom use cannot predict sexual behaviour. Literature by Castora (2005), showed that participants had knowledge about HIV and AIDS, and STI's, their behaviour left a lot to be desired because the participants did not practice safe sex. The study also found that 68 percent of male students had engaged in risky sexual behaviours under the influence of drugs or alcohol and 22 percent female students were also more likely to do the same. Similar findings were reported by Sohn and Chun (2007), who found that although men initiated sex, they had more multiple partners than women and both genders were equally likely to engage in inconsistent condom use, even when having sex with a high risk partner. This implies that both partners might have multiple partners and this could result in unsafe sex.

There is a relationship between HIV risk perception and sexual initiation; that is, sexually inexperienced youth who perceive themselves to be at high risk will be more likely than those who perceive themselves to be at lower risk to delay first sexual intercourse, and individuals who have had sex will perceive themselves at higher risk than those who are sexually inexperienced. One may question whether sexually inexperienced youth can have any perceived risk of HIV infection. However, sexually inexperienced youth may perceive themselves to be at risk if, for example, they doubt their ability to maintain consistent condom use or to identify partners who are at low risk of infection once they become sexually active In previous research in KwaZulu-Natal (a South African province with a high HIV prevalence), some youth with no HIV risk behaviours nonetheless perceived themselves as at risk of infection within the next 12 months. Sexually inexperienced youth who view themselves as at risk of HIV infection at some point in the future may try to delay first sex (the gateway to further HIV risk behaviours).

Being a student in a tertiary institution significantly increase ones odds of using a condom. In other words, students in a tertiary institution are less risk loving than young adults, in the same age range, that are not students. Being a student is associated with higher levels of education, cognitive capacity and knowledge of HIV, which would all contribute to a greater prevalence of condom use; but even when controlling for these factors, using albeit imperfect proxies for them, being a student has a significantly positive relationship with condom use. This indicates that there may be other factors encompassed by the student lifestyle, be that the promotion of HIV awareness at universities is more effective at changing behaviour than other interventions which simply give people knowledge about HIV.

\section{References}

Adetunji, J., and Meekers, D. 2001. Consistency in Condom Use in the Context of HIVIAIDS in Zimbabwe. Joural of Biosocial Science 33, 121-138.

Ajzen I and Fishbein M. 1980. Understanding Attitudes and Predicting Social Behavior, Englewood Cliffs, NJ, USA: Prentice Hall.

ASSA. 2008. ASSA 2008 Model. Retrieved September 17, 2013, from AIDS Committee of the Actuarial Society of South Africa: http://aids.actuarialsociety.org.za/ASSA2008-Model-3480.htm

Barden-O'Fallon J.L. 2004, Factors associated with HIVIAIDS knowledge and risk perception in rural Malawi, AIDS and Behavior, 2004, 8(2):131-140.

Bezabih, M., Mannberg, A., and Visser, M. 2010. Sexual Risk Taking Among Young Adults in Cape Town: Effects of Expected Health and Income. A Southern Africa Labour and Development Research Unit Working Paper Number 43. Cape Town: SALDRU, University of Cape Town. 
Burgard, S. A., Kusunoki, Y., and McGraw, M. 2008. Condom Use among Black Youth in South Africa: Do Relationship Characteristics Matter?

Camlin CS and Chimbwete CE. 2003. Does knowing someone with AIDS affect condom use? An analysis from South Africa, AIDS Education and Prevention. 15(3):231-244.

Castora M. 2005. The Assessment of University Students' Knowledge, Attitudes, and Behaviours towards Sex. University of Central Florida Undergraduate. Florida: US.

Cong L, Kihara M, Ma Q, Ono-Kihara M, Ravar, SM, Xu G. and Zamani S 2006.

Sexual behavior and awareness of Chinese university students in transition with implied risk of sexually transmitted diseases and HIV infection: A cross-sectional study.

Eaton L and Flisher AJ. 2000. HIVIAIDS knowledge among South African youth, Southern African Journal of Child and Adolescent Mental Health. 12(2):97-124.

Gersovitz M. 2005. The HIV epidemic in four African countries seen through the Demographic and Health Surveys, Journal of African Economies, 2005, 14(2):191-246.

Grebe, E., and Nattrass, N. 2011. AIDS Conspiracy Beliefs and Unsafe Sex in Cape Town. AIDS Behaviour . HIV In-Site. 2001. SubSaharan Africa.

Human Science Research Council. 2002. Nelson Mandela/HSRC Study of HIVIAIDS. Cape Town: HSRC.

Kamali V, Li X, Naar-King S, Shah I, Stanton B, Thomas R. and Wang B. 2007. Sexual attitudes, pattern of communication, and sexual behaviour among unmarried out-of-school youth in China.

Leigh, B. C. 2002. Alcohol and Condom Use: A Meta-Analysis of Event-Level Studies. Sexually Transmitted Diseases 29 (8), $476-482$.

Macintyre K. 2004. Understanding perceptions of HIV risk among adolescents in KwaZulu-Natal, AIDS and Behavior, HIV and Sexual Behaviour among Young South Africans: A National Survey of 15-24 Year Olds, Johannesburg, South Africa: Reproductive Health Research Unit, University of Witwatersrand.

Macintyre K, Brown L and Sosler S. 2001. It is not what you know, but who you knew: examining the relationship between behavior change and AIDS mortality in Africa, AIDS Prevention and Education, 2001, 13(2):160-174

Mah, T. L., and Maughan-Brown, B. 2009. Social and Cultural Contexts of Concurrency in Khayelitsha. CSSR Working Paper No. 251

Maharaj P. 2006. Reasons for condom use among young people in KwaZulu-Natal: prevention of HIV, pregnancy or both? International Family Planning Perspectives. 32(1):28-34.

Maughan-Brown BG. 2006. Attitudes towards people with HIVIAIDS: stigma and its determinants among young adults in Cape Town, South Africa, South African Review of Sociology. 37(2):165-188.

Moore S and Rosenthal D. 1991. Adolescent invulnerability and perceptions of AIDS risk, Journal of Adolescent Research, 1991, 6(2):164-180.

Mwaba K. and Naidoo P. 2005. Sexual practices, attitudes toward pre-marital sex and condom use among a sample of South African university students. Social Behaviour and Personality: An International Journal, 33(7): 651 - 656.

Peltzer, K. 2000. Factors Affecting Condom Use Among South African University Students. East African Medical Journal 77 (1), $46-52$.

Peters, E., Baker, D. P., Dieckmann, N. F., Leon, J., and Collins, J. 2010. Explaining the Effect of Education on Health : A Field Study in Ghana. Psychological Science, 21 (10), 1369-1376.

Pithey, A. L., and Morojele, N. K. 2002. Literature Review on Alcohol Use and Sexual Risk Behaviour in South Africa. Alcohol and Drug Abuse Research Unit

Shisana O. 2005. South African National HIV Prevalence, HIV Incidence, Behaviour and Communication Survey, 2005, Cape Town, South Africa: Human Sciences Research Council Press.

Shobo Y. 2007. Youth's perceptions of HIV infection risk: a sex-specific test of two risk models, African Journal of AIDS Research. 6(1):1-8.

Simbayi LC, Chauveau J and Shisana O. 2004.Behavioural responses of South African youth to the HIVIAIDS epidemic: a nationwide survey, AIDS Care. 16(5):605-618.

Smith RA and Morrison D. 2006. The impact of stigma, experience, and group referent on HIV risk assessments and HIV testing intentions in Namibia, Social Science \& Medicine. 63(10):2649-2660.

Sohn A, Chun SS. 2007.Gender differences in sexual behavior and condom-related behaviours and attitudes among Korean youths, Asia Pacific Journal of Public Health, 19(2): 45-52.

Ukwuani FA, Tsui AO and Suchindran CM. 2003. Condom use for preventing HIV infections/AIDS in Sub-Saharan Africa: a comparative multilevel analysis of Uganda and Tanzania, Journal of Acquired Immune Deficiency Syndromes. 34(2):203-213.

UNAIDS. 2010. Global report: UNAIDS report on the global AIDS epidemic 2010.

WHO/UNAIDS. 2000. The HIV.AIDS pandemic and its gender implications.

Retrieved September 10, 2013, from Report of the Expert Group Meeting: http://www.un.org/womenwatch/daw/csw/hivaids/report.pdf 